\title{
Novel Synthesis of Gel Capsule by Esterification of Poly(acrylic acid) Gel
}

\author{
Fumihiko Matsuda, Shun Miyamoto, and Takashi IIzawa ${ }^{\dagger}$ \\ Department of Chemical Engineering, Faculty of Engineering, Hiroshima University, \\ Kagamiyama, Higashi-Hiroshima 739-8527, Japan
}

(Received October 12, 1998)

\begin{abstract}
To synthesize a novel gel capsule containing a hydrophobic shell and hydrophilic core portions, we investigated the esterification of poly(acrylic acid) gel-1,8-diazabicyclo[5,4,0]undec-7-ene salt (DAA) with alkyl bromides. The esterification of DAA with benzyl bromide proceeded almost quantitatively in $N$-methyl-2-pyrrolidone (NMP) from the surface, although small amounts of carboxylic acids were produced as side products. The reaction gave a new gel capsule consisting of a hydrophilic unreacted core and hydrophobic esterified shell, and finally afforded poly(benzyl acrylate) gel. Reactions of DAA with alkyl bromides were carried out under various conditions, and analyzed kinetically. The observed reaction rate markedly affected the molecular size of the alkyl halides and solvents rather than reactivity of their combinations. This suggests that the overall reaction depends markedly on diffusion rate of alkyl bromides and solvents through the reacted shell layer. The thickness of the shell layer was easily controlled by reaction conditions. The swelling of the gel capsule and release of Rose-Bengal from the gel capsule were studied. The results suggested that the structure of the shell layer controls properties such as the swelling rate, burst time, and releasing rate of chemicals.

KEY WORDS Gel Capsule / Esterification / Poly(acrylic acid) / 1,8-Diazabicyclo[5,4,0]undec-7-ene / Chemical Release /
\end{abstract}

Neutralized poly(acrylic acid) gels are famous as superabsorbent gels. ${ }^{1}$ The gels are able to soak up to one thousand times their own weight of pure water. Applications such as disposal diapers have been developed based on this swelling. Also, they store many water-soluble chemicals. However, water-swollen gels are easily broken, although the surface coating and surface crosslinking with glycerin ${ }^{2}$ or ethylene glycol diglycidyl ether ${ }^{3}$ are performed to improve swelling rate. Therefore, they are not used widely for storage and release of chemicals. The synthesis of $100 \mu \mathrm{m}$ order size of core-shell type particles; hydrophilic neutralized poly(acrylic acid) gels covered with hydrophobic poly(alkyl acrylate) shell layer has been reported by two-stage reverse suspension polymerization. ${ }^{4}$ This hydrophobic shell layer would not only reinforce the gel, but also control the chemical release and occlusion. However, the boundary between core and shell does not have enough strength to cope with strong swelling pressure of the neutralized poly(acrylic acid) core, and the gel breaks easily when swollen in water.

Recently, we investigated a new reinforced core-shell type gel "gel capsule" composed of a continuous network between a hydrophilic core and hydrophobic shell parts. The gel capsule would be more durable for swelling or deswelling than the normal core-shell type gel consisting of two distinct networks of core and shell. The gel capsule can be synthesized according to two synthetic routes. One is the selective thermal acid-catalyzed deesterification of internal poly( $t$-butyl methacrylate) gel. ${ }^{5}$ The other is selective esterification of external poly(carboxylic acid) gels. The esterification of linear poly(carboxylic acid) has been investigated by many methods. ${ }^{6,7}$ In these methods, the reaction of poly(carboxylic acid) with an alkyl halide is suitable for chemical modification using 1,8-diazabicyclo[5,4,0]undec-7-ene (DBU) as an acid acceptor, because quantitative esterification is achieved by this method in a short time under mild conditions. ${ }^{7 \mathrm{c}, \mathrm{f}}$
Previous communication ${ }^{8}$ reports that heterogeneous esterification of DBU salt (DAA) of poly(acrylic acid) gel with alkyl bromide proceeds in an aprotic polar solvent from the surface into the interior to give the corresponding poly(alkyl acrylate) gel through the gel capsule. Reactions of DAA with alkyl chlorides also afford gel capsules, ${ }^{9}$ and can be simulated using the homogenous model. ${ }^{10}$ However, the reaction mode of DAA with alkyl bromide is very different from that with alkyl chloride, ${ }^{9}$ and the detailed reaction mechanism has not been determined.

This paper reports the esterification of DBU, triethylamine (TEA), and sodium salts of poly[(meth)acrylic acid] gel with alkyl bromides in a solvent to determine the reaction mechanism (Scheme 1). Esterification from the outer gives a gel capsule consisting of a hydrophilic unreacted core and a hydrophobic esterified shell (Scheme 2). We discuss the swelling of the obtained gel capsule and release of chemicals from the gel.

\section{EXPERIMENTAL}

\section{Materials}

Monomers and solvents were distilled prior to use. Commercial alkyl halides were used as purchased. $N, N^{\prime}$ methylenebisacrylamide, sodium chloride, DBU, TEA, tetrabutylammonium bromide (TBAB), and tetraethylammonium bromide (TEAB) were used without further purification. Cylindrical DAA (length and diameter: 3, 5 , and $7 \mathrm{~mm}$ ) was prepared as reported previously. ${ }^{8,9}$ The neutralization of DAA was $98 \%$ calculated by the back-titration using $0.1 \mathrm{~N}$ aqueous $\mathrm{HCl}$ solution- $0.05 \mathrm{~N}$ aqueous $\mathrm{NaOH}$ solution. Poly(methacrylic acid) gelDBU salt (DMA), poly(acrylic acid) gel-sodium salt (NAA), and poly(acrylic acid) gel-TEA salt (TAA) were prepared by the neutralization of the corresponding poly(carboxylic acid) gels with bases in the same way.

\footnotetext{
† To whom all correspondence should be addressed.
} 

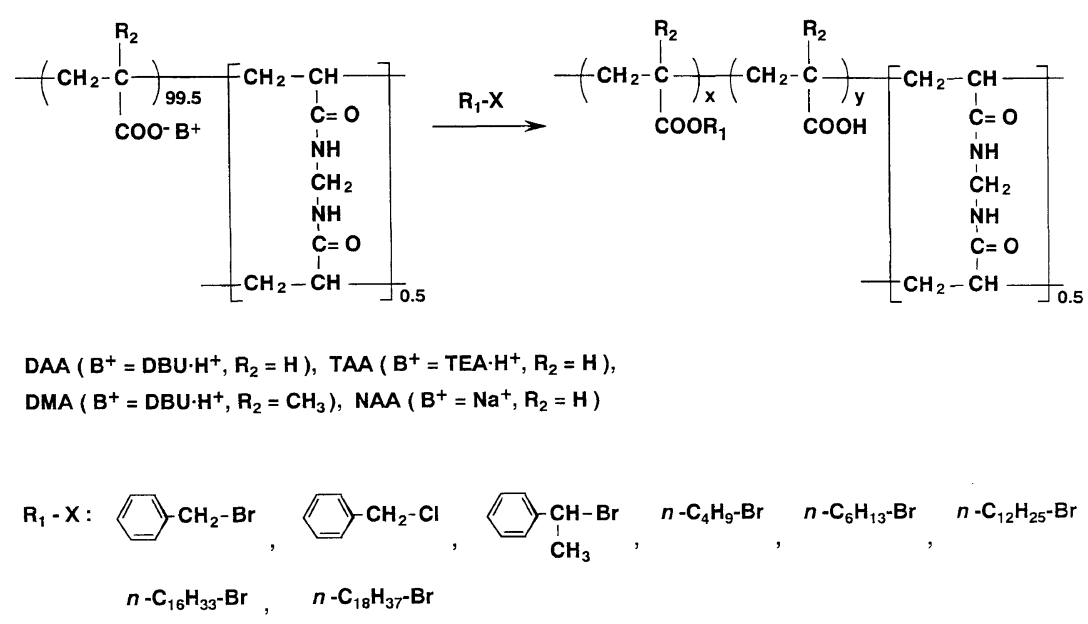

Scheme 1. Esterification of poly(acrylic acid) salts with alkyl halides.

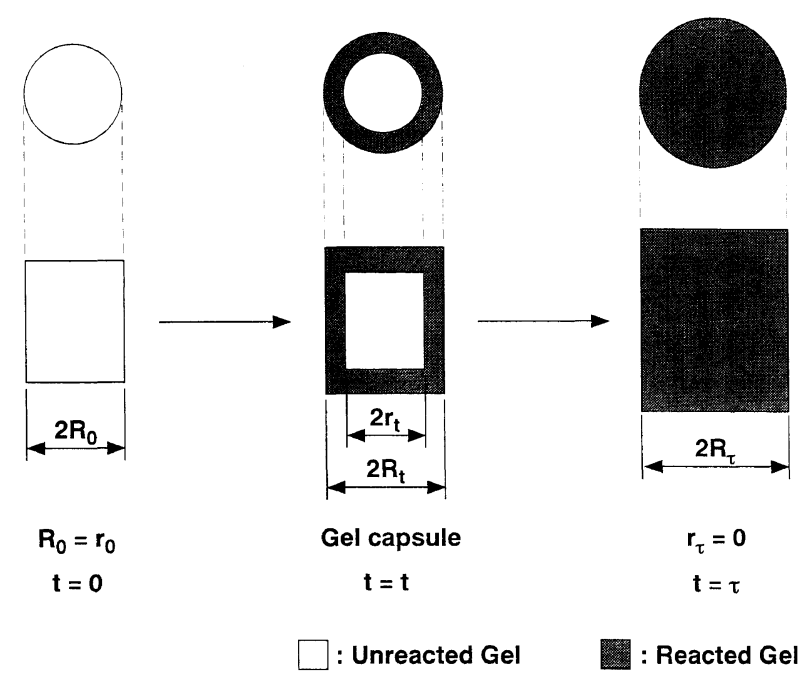

Scheme 2. Changes in shape of gel in reaction.

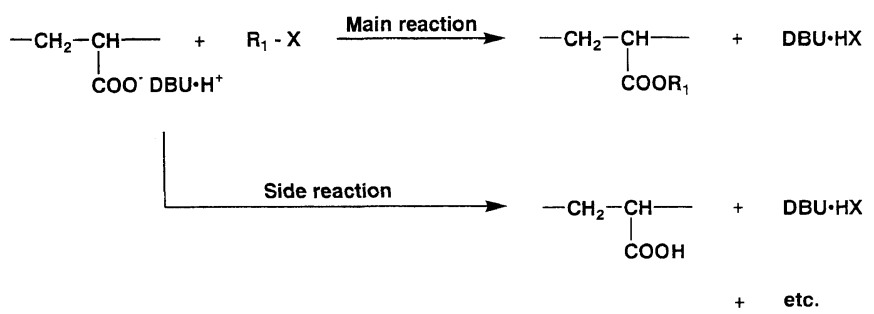

Scheme 3. Reaction mechanism of DBU salt of carboxylic acid with alkyl halide.

\section{Apparatus}

The reaction was recorded by a SONY model DCR-VX 1000 digital video camera. IR spectra were obtained on a JASCO model IR-700 spectrophotometer. UV spectra were measured on a Shimadzu model UV 2100S spectrophotometer.

\section{Esterification of $D A A$ and Measurement}

A typical esterification was as follows. Benzyl bromide solution in $N$-methyl-2-pyrrolidone (NMP) $\left(1.0 \mathrm{~mol} \mathrm{~L}^{-1}\right.$, $50 \mathrm{~mL}$ ) was charged into a $50 \mathrm{~mL}$ cylindrical cell in a water bath at $80^{\circ} \mathrm{C}$. To the solution was added a sample of DAA $(0.301 \mathrm{~g})$. The gel began swelling and divided into a swollen shell and unswollen core. The reaction was recorded by a digital video camera. The radii of the shell and core, $R_{\mathrm{t}}$ and $r_{\mathrm{t}}$, after $t$ min were measured by microcomputer imaging. After the disappearance of the core, the esterified gel was washed with acetone by a Soxhlet extractor and dried in vacuo at $110^{\circ} \mathrm{C}$ until constant weight. The weight of the esterified gel was $0.209 \mathrm{~g}$. The gel was dipped in TEA solution in tetrahydrofuran (THF) $\left(10 \mathrm{mmol} \mathrm{L}^{-1}, 25 \mathrm{~mL}\right)$ at room temperature for $24 \mathrm{~h}$. Free carboxylic acid in the gel was determined by neutralization titration of the filtrate with $0.01 N$ aqueous $\mathrm{HCl}$ solution. Esterification calculated from the back-titration and from the change of weight before and after the reaction was $91 \%$ and $92 \%$, respectively.

\section{Chemical Release from the Gel Capsule}

The gel capsule was dipped into a solution $(0.1 \mathrm{mmol}$ $\left.\mathrm{L}^{-1}\right)$ of Rose-Bengal in methanol-acetone mixture $(1: 1)$ 


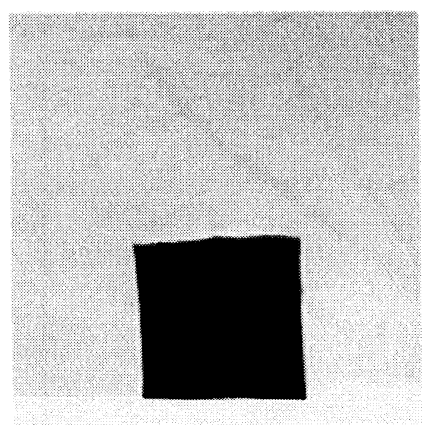

$0 \min$

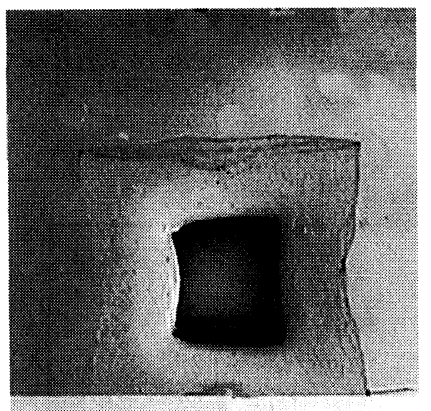

$240 \mathrm{~min}$

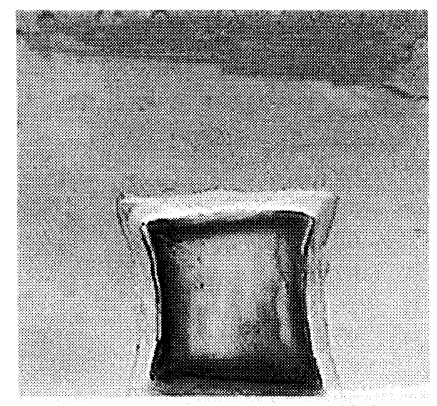

$30 \mathrm{~min}$

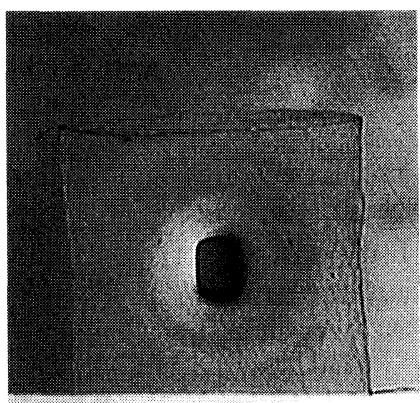

$360 \min$

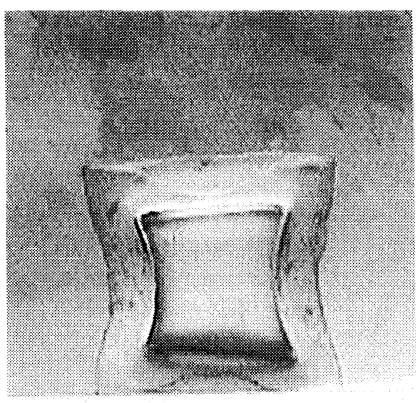

$120 \mathrm{~min}$

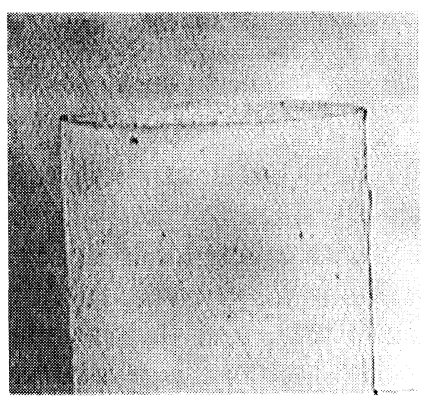

$510 \mathrm{~min}$

Figure 1. Typical photographs in reaction of DAA with benzyl bromide in NMP at $80^{\circ} \mathrm{C}$.

and allowed to swell for 1 day at $30^{\circ} \mathrm{C}$. After drying, the shell layer was selectively washed with acetone by a Soxhlet extractor and dried again. The sample was placed in $300 \mathrm{~mL}$ water or aqueous $1 \mathrm{wt} \% \mathrm{NaCl}$ solution at $50^{\circ} \mathrm{C}$. $A_{\mathrm{t}}$, absorbance of the solution at $548 \mathrm{~nm}$ after $t$ min, was measured by a UV spectrophotometer.

\section{RESULTS AND DISCUSSION}

Synthesis of Gel Capsule by Esterification of Poly(acrylic acid) Gel

Salts of poly(acrylic acid) gel with DAA, NAA, and TAA were prepared by the copolymerization of acrylic acid with $0.5 \mathrm{~mol} \%$ of $N, N^{\prime}$-methylenebisacrylamide in Teflon tubes. Neutralization of the resulting gel was conducted with excess bases such as DBU, sodium hydroxide, and TEA in methanol. DMA was prepared from reaction of poly(methacrylic acid) gel with DBU. DAA did not swell in usual solvents except water, alcohols, and dimethyl sulfoxide (DMSO). When cylindrical DAA (length the same as diameter; $7 \mathrm{~mm}$ ) was placed in NMP containing excess benzyl bromide at $80^{\circ} \mathrm{C}$, swelling occurred, and DAA was divided into a swollen shell and unswollen core (Figure 1). The shell expanded with decreasing radius $\left(r_{t}\right)$ of the core. The cylindrical shape of core was similar to the original until high conversion. The radius $\left(R_{\mathrm{t}}\right)$ of shell increased gradually for a long time after the core disappeared. The resulting shell layer did not swell in water or methanol, although the hydrophilic core swelled well in these solvents. The IR spectrum of the shell part is shown in Figure 2. The spectrum showed strong absorption of ester at $1733 \mathrm{~cm}^{-1}(\mathrm{C}=\mathrm{O}$ of ester, stretching), and wide absorption at $2500-3500 \mathrm{~cm}^{-1}$ and discernible shoulder

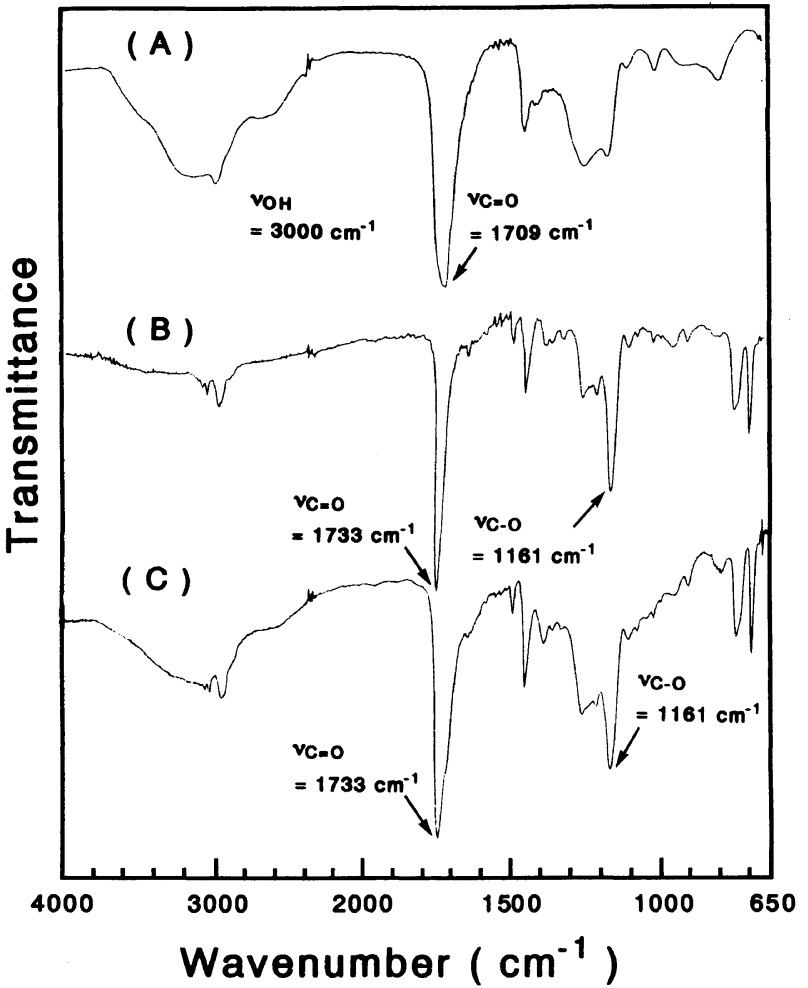

Figure 2. IR spectra. (A) soluble poly(acrylic acid); (B) soluble poly(benzyl acrylate); (C) poly(benzyl acrylate) gel.

near $1710 \mathrm{~cm}^{-1}$ based on free carboxylic acid. This seems to agree with that of poly(benzyl acrylate) containing small amounts of acrylic acid unit. The reaction of DAA with an alkyl halide can be explained by Scheme 3 . When excess alkyl halide and DBU were used, esterification of 
Table I. Reactions of poly(acrylic acid) salt with alkyl bromides in NMP at $80^{\circ} \mathrm{C}$

\begin{tabular}{|c|c|c|c|}
\hline \multirow{2}{*}{$\begin{array}{l}\text { Poly(acrylic } \\
\text { acid) }\end{array}$} & \multirow{2}{*}{$R$} & \multirow{2}{*}{$\frac{\text { Conv. }^{a}}{\%}$} & \multirow{2}{*}{$\frac{\text { Conv. }^{b}}{\%}$} \\
\hline & & & \\
\hline DAA & Benzyl bromide & 91 & 92 \\
\hline DAA & 1-Phenylethy bromide & 83 & 81 \\
\hline DAA & $n$-Butyl bromide & 94 & 96 \\
\hline DAA & $n$-Hexyl bromide & 90 & 92 \\
\hline DAA & $n$-Dodecyl bromide & 89 & 90 \\
\hline DAA & $n$-Hexadecyl bromide & 93 & 89 \\
\hline DAA & n-Octadecyl bromide & 92 & 90 \\
\hline NAA & Benzyl bromide + TEAB $^{c}$ & 75 & - \\
\hline NAA & Benzyl bromide + TBAB $^{\mathrm{c}}$ & 72 & - \\
\hline TAA & Benzyl bromide & 85 & 82 \\
\hline
\end{tabular}

${ }^{a}$ Obtained by neutralization analysis. ${ }^{\mathrm{b}}$ Obtained by weight change. ${ }^{c} 4 \mathrm{mmol}$ of tetraalkylammonium bromide was used as PTC.

carboxylic acid-DBU salt with alkyl halide proceeded quantitatively since the resulting by-product carboxylic acid reacts with excess DBU to reproduce the DBU salt. This reaction was carried out in the presence of equimolar amount of DBU, and thus a small amount of acrylic acid unit remained in the gel as a by-product. Carboxylic acid in the reacted gel was determined by back-titration using TEA solution-aqueous $\mathrm{HCl}$ solution (Table I). Esterification of gels obtained from the complete reaction was calculated from change of weight before and after reaction. Esterification of gels calculated by both methods was almost the same, and the reaction gave gels with more than $90 \mathrm{~mol} \%$ esterification, except for the reaction with secondary 1 -phenylethyl bromide. Esterification is thus very high in the swollen parts, and the shell is the corresponding poly(alkyl acrylate) gel with small amounts of carboxylic acids. The reaction proceeded gradually from the surface of DAA to the interior to give an amphiphilic core-shell. The reaction mode was different from that of DAA with alkyl chloride reported previously. ${ }^{9}$

The reaction has three rates; intrinsic esterification rate of DBU salt of carboxylic acid with alkyl bromide, diffusion rate of alkyl bromide through a swollen part, and diffusion rate of alkyl bromide through an unswollen part. The diffusion rate through the swollen part is much faster than that through an unswollen part in the system. Reactions of carboxylic acids-DBU salts with alkyl bromides are very fast in aprotic polar solvents. ${ }^{7}$ Reactions of DBU salts of benzoic acid and linear poly(methacrylic acid) with alkyl bromide proceeded quantitatively at $30^{\circ} \mathrm{C}$ within $10 \mathrm{~min}$ and $1 \mathrm{~h} .{ }^{11,7 \mathrm{c}, \mathrm{f}}$ Only the part with high esterification swells in the solvent. The rate of intrinsic esterification of DAA with alkyl bromide and diffusion rate through a swollen part are thus much faster than the diffusion rate through an unswollen part, and the reaction zone is restricted to the boundary between the swollen part and the unswollen part as shown in Scheme 2. This is similar to the unreacted-core model well-known for burning of cokes and roasting of ores, ${ }^{12}$ and is different from that of DAA with less reactive alkyl chloride affected strongly by the diffusion through an unswollen part $^{9}$ and simulated by the homogenous model. ${ }^{10}$ The unreacted-core model has the following two rate-controlling steps.

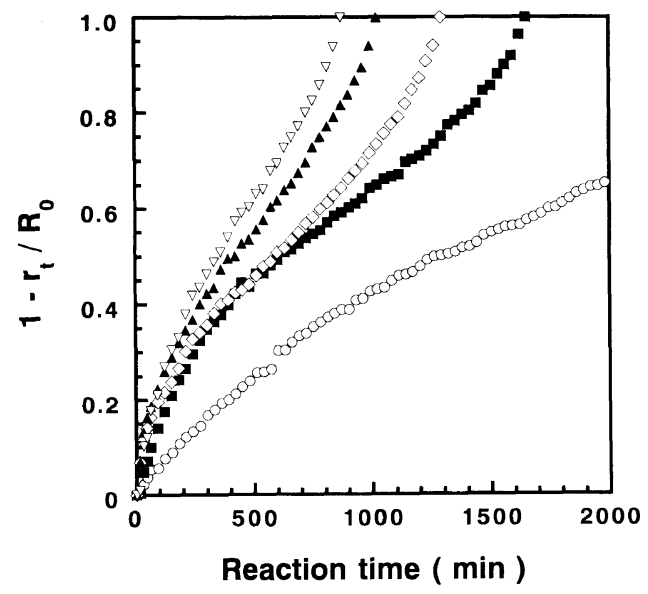

Figure 3. Effects of temperature on reactions of DAA with benzyl bromide in NMP at $[\nabla] 80^{\circ} \mathrm{C} ;[\mathbf{\Delta}] 70^{\circ} \mathrm{C} ;[\diamond] 60^{\circ} \mathrm{C}$; [ $] 50^{\circ} \mathrm{C}$; [O] $30^{\circ} \mathrm{C}$.

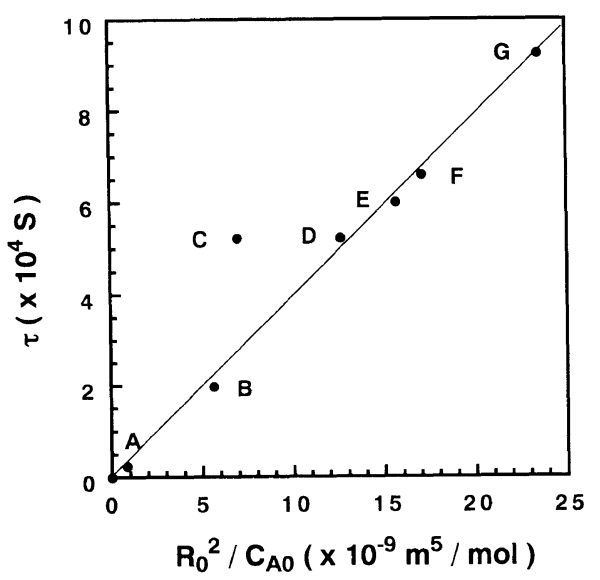

Figure 4. Relations between $R_{0}^{2} / C_{\mathrm{A} 0}$ and $\tau$ in NMP at $80^{\circ} \mathrm{C}$.

Step 1. When the esterification rate is much slower than the diffusion rate through the swollen part, the rate-controlling step is the intrinsic esterification. Reaction time $(t)$ is proportional to decreasing of the radius of the core part as shown in eq 4 , where the time for complete reaction of the gel is $\tau$.

$$
t / \tau=1-r_{\mathrm{t}} / R_{0}
$$

Step 2. When the esterification rate is much faster than the diffusion rate through the swollen part, the resistance to diffusion through a swollen part controls the reaction. The observed $1-r_{\mathrm{t}} / R_{0}$ is larger than $t / \tau$ at the initial reaction, because diffusion resistance of the shell layer increases with thickness.

Esterification of DAA was carried out under various conditions. The rate of disappearance of the core part increased with reaction temperature (Figure 3). The observed $1-r_{\mathrm{t}} / R_{0}$ was larger than $t / \tau$ at the initial reaction. If a gel is considered an infinite cylinder and intrinsic reaction is the rate-controlling step of the unreacted-core model, $\tau$ exhibits eq 5 , where $C_{\mathrm{A} 0}$ is the initial concentration of alkyl halide. ${ }^{12 \mathrm{~b}}$ However, $\tau$ did not agree with eq 5 , but was proportional to $R_{0}^{2} / C_{\mathrm{A} 0}$ except for C (Figure 4). A, B, C, D, E, F, and G in this figure show the conditions of the experiment (Table II). $\mathrm{C}$ shows that the concentration of benzyl bromide as 
Table II. Reactions of DAA with alkyl bromides in NMP at $80^{\circ} \mathrm{C}$

\begin{tabular}{lccccccc}
\hline \multicolumn{1}{c}{ Sample } & A & B & C & D & E & F & G \\
\hline$R_{0} / \mathrm{mm}^{\text {Ao }} / \mathrm{mol} \mathrm{L}^{-1}$ & 0.90 & 2.37 & 3.54 & 3.56 & 3.56 & 3.58 & 3.58 \\
$\tau \times 10^{4} / \mathrm{S}$ & 0.25 & 1.00 & 2.00 & 1.00 & 0.75 & 0.66 & 0.50 \\
& & & 5.22 & 5.22 & 6.00 & 17.09 & 23.46
\end{tabular}

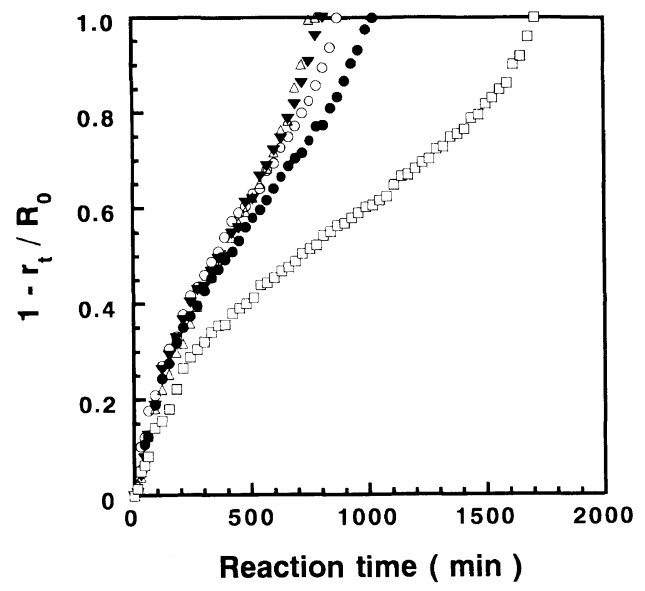

Figure 5. Reactions of DAA with various alkyl halides in NMP at $80^{\circ} \mathrm{C}$. [ $\triangle$ ] $n$-butyl bromide; [ $\mathbf{\nabla}$-hexyl bromide; [O] benzyl bromide; [O] benzyl chloride; [ $\square]$ 1-phenylethyl bromide.

more than $20 \mathrm{vol} \%$ and so high that the solution was not regarded as NMP. Intrinsic esterification is thus not the rate-controlling step. This relation (eq 6) holds when the diffusion though the shell layer is the rate-controlling step of the unreacted-core model for unchanging shell size. ${ }^{12 b}$ This cannot mean directly that the diffusion though the swollen part is the rate-controlling step because an external diameter of shell layer increased during the reaction and the diffusion constant was not uniform in the swelled layer. However, the reaction is strongly affected by mass transfer through the swollen part. Under these conditions, the observed reaction rate is associated with molecular size of the used alkyl bromide or solvent.

$$
\begin{gathered}
\tau \propto \frac{R_{0}}{C_{\mathrm{A} 0}} \\
\tau \propto \frac{R_{0}^{2}}{C_{\mathrm{A} 0}}
\end{gathered}
$$

The reaction was carried out with various alkyl halides such as benzyl bromide, $n$-butyl bromide, $n$-hexyl bromide, and 1-phenylethyl bromide in NMP (Figure 5). The reaction of DAA with benzyl bromide was completed a little more slowly than that with $n$-butyl bromide and $n$-hexyl bromide, although benzyl bromide showed a higher reactivity than the other alkyl bromides in the corresponding homogeneous esterification. Bulky 1phenylethyl bromide showed much lower reactivity than benzyl bromide. The esterification of DAA was studied with various $n$-alkyl bromides containing long alkyl chains such as $n$-decyl bromide, $n$-hexadecyl bromide, and $n$-octadecyl bromide, which would show almost the same reactivity in the intrinsic esterification (Figure 6). The exact $\tau$ was not detected in the reaction of DAA

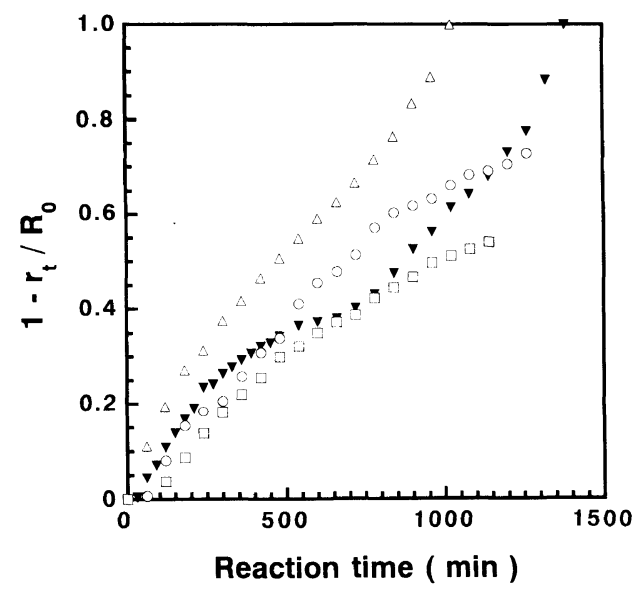

Figure 6. Reactions of DAA with $n$-alkyl bromides. ${ }^{a}[\triangle] n$-hexyl

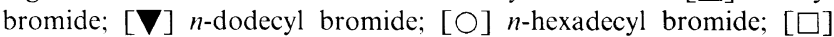
$n$-octadecyl bromide. ${ }^{\mathrm{a}} C_{\mathrm{A} 0}=0.5 \mathrm{~mol} \mathrm{~L}^{-1}$.

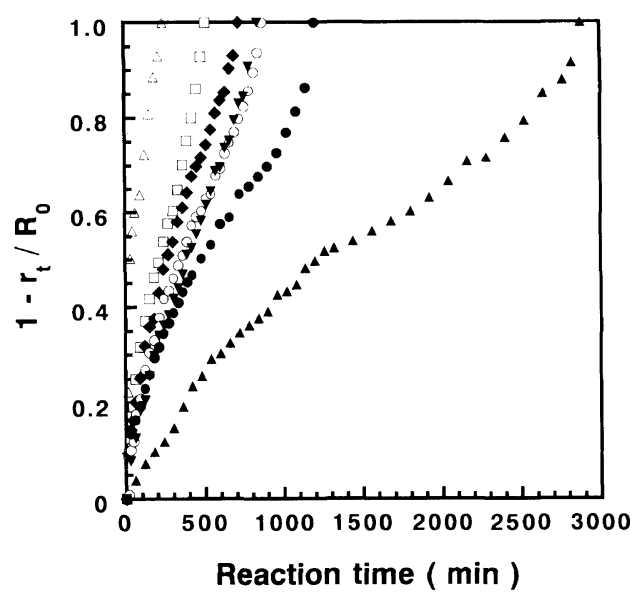

Figure 7. Reactions of DAA with benzyl bromide in various solvents

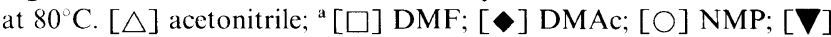
DMSO; $[\mathbf{\bullet}]$ nitrobenzene; $[\mathbf{\Delta}]$ 1,4-dioxane.

${ }^{2}$ The reaction was carried out at $70^{\circ} \mathrm{C}$

with $n$-hexadecyl bromide and $n$-octadecyl bromide because the gels with high esterification floated on the solvent. From the figure, $\tau$ can be estimated to increase with alkyl chain length of alkyl bromide. The reaction may thus depend on the steric hindrance of alkyl bromides. Reaction with benzyl bromide was carried out at $80^{\circ} \mathrm{C}$ in various solvents (Figure 7). The reaction was very fast when performed in acetonitrile at $70^{\circ} \mathrm{C}$. The rate increased nearly with decreasing molecular size of solvent in following order; Acetonitrile $>N, N$ dimethylformamide (DMF) $>N, N$-dimethylacetamide (DMAc) $>$ NMP. Therefore, the reaction of DAA with alkyl bromides is strongly affected by the molecular size of alkyl bromides and solvents rather than intrinsic reactivity of their combinations. This means that the reaction depends markedly on the diffusion of the alkyl bromide solution in the swollen part.

Esterification with benzyl bromide was carried in NMP at $80^{\circ} \mathrm{C}$ using other salts of poly(acrylic acid) such as TAA and NAA (Figure 8). The reaction of TAA was slower than that of DAA. Similar results were observed in homogeneous esterification reactions such as the polycondensation of dicarboxylic acids with dihalides ${ }^{11}$ 


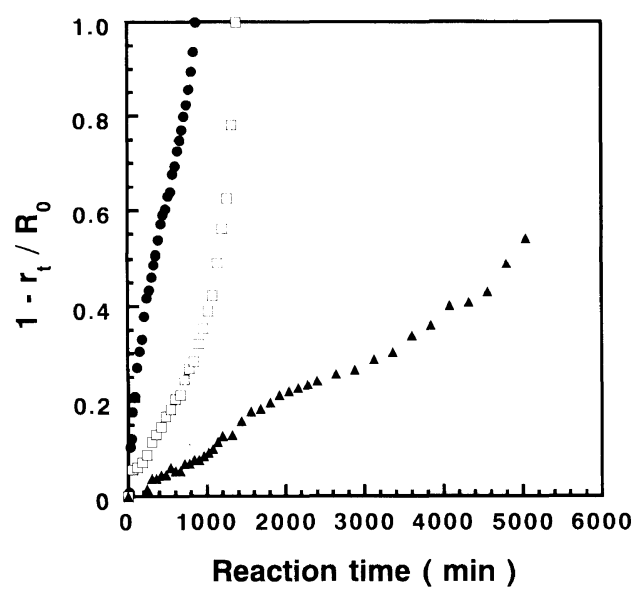

Figure 8. Esterification of TAA and NAA with benzyl bromide in NMP at $80^{\circ} \mathrm{C}$. [O] DAA; [ $\left.\square\right]$ TAA; [ $\left.\mathbf{\Delta}\right]$ NAA. ${ }^{a}$ a $4 \mathrm{mmol}$ of TBAB was used as a PTC.

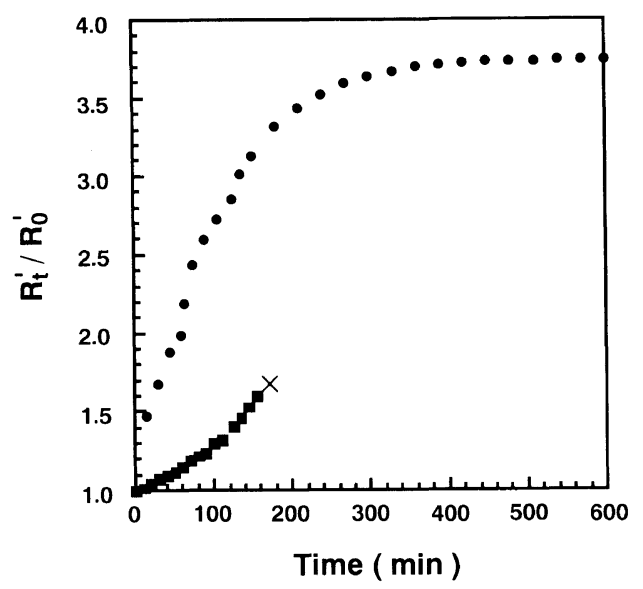

Figure 9. Swelling curves of gels in water at $50 \mathrm{C}$. [ ] DAA; [ $]$ gel capsule $\left(r_{\mathrm{t}} / R_{0}=0.8\right)$ prepared from reaction of DAA with hexyl bromide.

and esterification of benzoic acid with poly( $p$-chloromethylstyrene). ${ }^{13}$ The reactivity of the salt of carboxylic acid is attributed to the basicity of the base, because DBU $\left(\mathrm{p} K_{\mathrm{a}}=11.5\right)$ is a stronger base than TEA $\left(\mathrm{p} K_{\mathrm{a}}=\right.$ 10.9). DBU is bigger than TEA. This may influence the diffusion rate of a gel, and cause reactivity to change. The synthesis of gel capsules was tried by reaction of NAA with benzyl bromide in NMP at $80^{\circ} \mathrm{C}$. The reaction hardly took place without any phase transfer catalyst (PTC) because NAA is very hydrophilic and does not swell in a solvent. The addition of TBAB or TEAB as a PTC caused the reaction to proceed. However, the reaction was much slower than that of DAA. When NAA stood in the solution of benzyl bromide for about 1 day, the swollen layer was broken and became like a sherbet. Therefore, it is difficult to synthesize gel capsules from the reaction of NAA. Esterification of gels obtained from TAA and NAA was lower than that of DAA as shown in Table I. It is thus concluded that DAA is suitable for the synthesis of gel capsules.

\section{Properties of a Gel Capsule}

The swelling of gel capsules $\left(r_{t} / R_{0}=0.8\right)$ prepared from the reactions of DAA and DMA with hexyl bromide in $\mathrm{NMP}$ at $80^{\circ} \mathrm{C}$ for $1 \mathrm{~h}$ and $40 \mathrm{~min}$, was carried out in

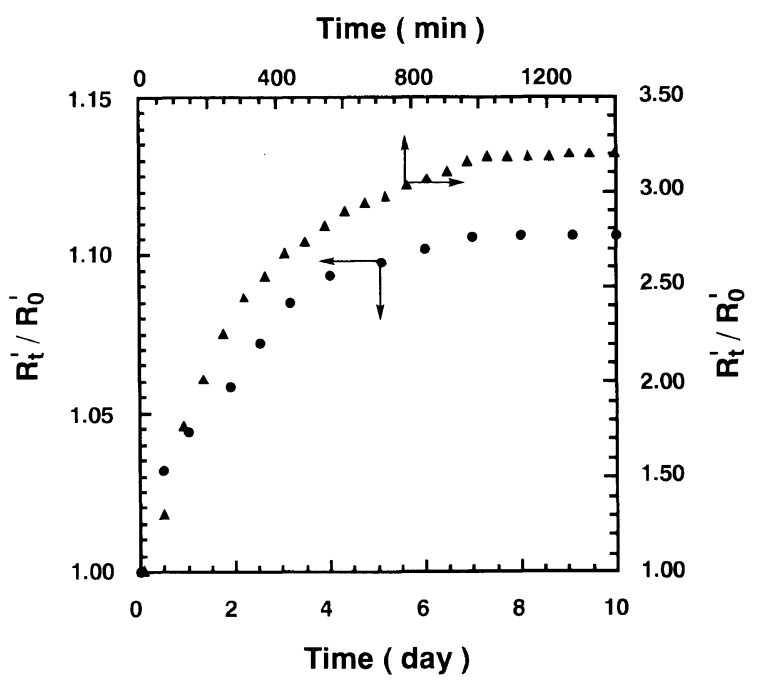

Figure 10. Swelling curves of gels in water at $50^{\circ} \mathrm{C}$. [ $\left.\mathbf{A}\right] \mathrm{DMA}$; [O] gel capsule $\left(r_{\mathrm{t}} / R_{0}=0.8\right)$ prepared from reaction of DMA with hexyl bromide.

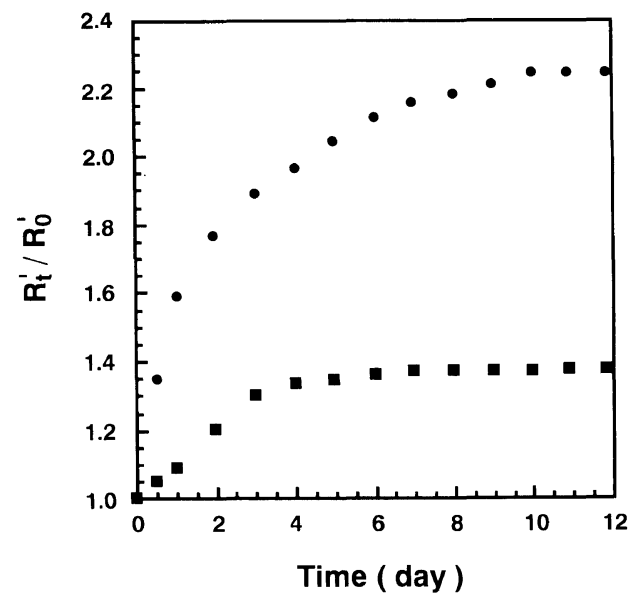

Figure 11. Swelling curves of gels in aqueous solution at $50 \mathrm{C}$. [O] gel capsule $\left(r_{\mathrm{t}} / R_{0}=0.8\right)$ in aqueous $1 \mathrm{wt} \% \mathrm{NaCl}$ solution; [ gel capsule $\left(r_{\mathrm{t}} / R_{0}=0.8\right)$ in aqueous $3 \mathrm{wt} \% \mathrm{NaCl}$ solution.

water at $50^{\circ} \mathrm{C}$ as shown in Figures 9 and 10 . The swelling was evaluated by $R_{\mathrm{t}}^{\prime} / R_{0}^{\prime}$, where $R_{0}^{\prime}$ and $R_{\mathrm{t}}^{\prime}$ are external radii of the dried gel and the gel swelled in the solvent for $t \mathrm{~min}$, respectively. Although the core part swelled in water, the swelling of the gel capsules was slower than that of the unreacted DBU salts. This suggests that the shell layer prevents swelling of the core part. The swelling of gel capsules obtained from DMA and unreacted DMA reached the equilibrium swelling radius. However, the gel capsule obtained from DAA swelled faster than that obtained from DMA, and burst in a few hours. This means that the shell layer composed of poly(alkyl acrylate) is too soft to cope with strong swelling pressure of the neutralized poly(acrylic acid) core. The swelling of the gel capsule obtained from DAA was tried in aqueous $1 \mathrm{wt} \%$ and $3 \mathrm{wt} \% \mathrm{NaCl}$ solutions at $50^{\circ} \mathrm{C}$ (Figure 11). The gel capsule was not broken under these conditions, and showed slower swelling than DAA. The rate of swelling decreased with increase of concentration of aqueous $\mathrm{NaCl}$ solution.

Release of Rose-Bengal from the gels was carried out in aqueous $1 \mathrm{wt} \% \mathrm{NaCl}$ solution at $50^{\circ} \mathrm{C}$ using the gel 


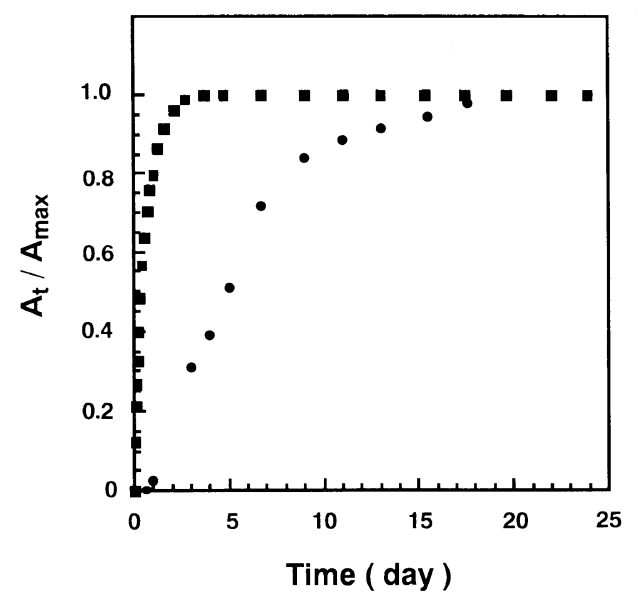

Figure 12. Change in absorbance of aqueous solution with a gel at 50 C: [ ] DAA with Rose-Bengal; [ $]$ gel capsule $\left(r_{1} / R_{0}=0.8\right)$ containing Rose-Bengal in the core part.

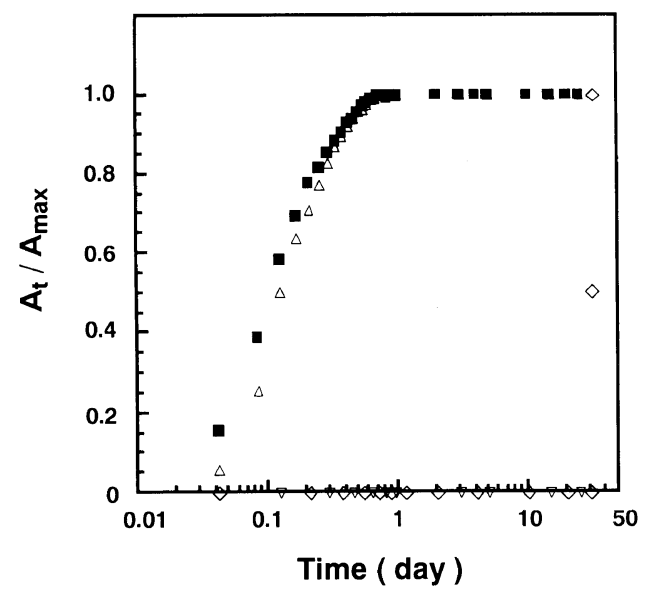

Figure 13. Change in absorbance of aqueous solution with a gel at $50 \mathrm{C}$ : [ $]$ DMA with Rose-Bengal; [ $\triangle$ ] gel capsule $\left(r_{1} / R_{0}=0.95\right)$; $[\nabla]$ gel capsule $\left(r_{1} / R_{0}=0.9\right)$; $[\diamond]$ gel capsule $\left(r_{1} / R_{0}=0.8\right)$. All gel capsules contained Rose-Bengal in the core part.

capsule $\left(r_{\mathrm{t}} / R_{0}=0.8\right)$. Typical release of Rose-Bengal is shown in Figure 12. DAA containing Rose-Bengal was used as a normal drug carrier to compare with the gel capsule. The gel capsule showed characteristic chemical release, where the release of Rose-Bengal from DAA took place with swelling of the gels. The release from gel capsule did not occur for 1 day until Rose-Bengel in the core part passed through the shell layer. After the induction period, chemical release from gel capsule started. The release was slower than that of DAA, and the $A_{\mathrm{t}} / A_{\infty}$ increased linearly with time until high degree of release. Gel capsules obtained from DMA with various thicknesses of shell layer were dipped in water at $50^{\circ} \mathrm{C}$ (Figure 13). The burst time became longer with increase of thickness of shell layer. The gel capsule having the thickest shell layer $\left(r_{\mathrm{t}} / R_{0}=0.8\right)$ was not broken when dipped in water for more than 100 days. The release of dye from the gel capsules was not observed until broken, where release from DMA was complete in 1 day. After the burst time, the release took place similarly to that from DMA. The shell layer thus inhibits the chemical release of Rose-Bengal. Since burst time can be controlled by the thickness of shell layer, the gel capsule should be applicable to drug carriers with a new function: chemical release starts after a definite (burst) time.

It is concluded that amphiphilic gel capsule is prepared by the esterification of poly(acrylic acid) gel-DBU salt with alkyl bromide. The resulting shell layer works as a permeability barrier to chemicals and water, and the structure of the shell layer controls the rate of chemical release and burst time. The gel capsule is thus suitable for chemical release.

Acknowledgments. This work was partly supported by a Grant-in-Aid for Scientific Research (No. 08651053) from the Ministry of Education, Science, Sports and Culture of Japan, for which are grateful.

\section{REFERENCES}

1. a) F. Masuda, "Kokyushu Kobunshi," Kyoritsu Shuppan Inc., Tokyo, 1987. b) F. L. Buchholz, Chemtech., Sept., 38 (1994).

2. T. Tsubakimoto, T. Shimomura, and Y. Irie, French Patent 2,525,121; Chem. Abstr., 100, 140245m (1984).

3. H. Yamazaki, T. Kobayashi, and Y. Sumida, German Patent 3,331,644; Chem. Abstr., 100, 175998s (1984).

4. S. Hirokawa, S.Fujita, and K. Masamizu, Japan Patent 63,132,901; Chem. Abstr., 109, 150694n (1988).

5. T. Iizawa, T. Fujimoto, and F. Matsuda, Polvm. J., 29, 784 (1997).

6. H. L. Cohen, J. Polym. Sci., Polym. Chem. Ed., 14, 7 (1976).

7. (a) T. Shimokawa and T. Nishikubo, Kobunshi Ronbunshu, 44, 641 (1987); (b) T. Shimokawa and T. Nishikubo, Kobunshi Ronbunshu, 49, 577 (1992); (c) T. Nishikubo, T. Iizawa, A. Takahashi, and T. Shimokawa, J. Polym. Sci., Part A, Polym. Chem. 28, 105 (1990); (d) T. Iizawa, K. Nishiyama, and T. Nishikubo, J. Photopolym. Sci. Technol., 3, 125 (1990); (e) T. Iizawa, K. Nishiyama, and T. Nishikubo, J. Polym. Sci., Part A, Polym. Chem., 31, 443 (1993); (f) T. Iizawa and Y. Sato, Polvm. J., 24, 991 (1992); (g) T. Iizawa and E. Seno, Polym. J., 24, 1169 (1992); (h) T. Iizawa and T. Ogasa, J. Polvm. Sci., Part A, Polvm. Chem., 34, 63 (1996); (i) T. Nishikubo, A. Kameyama, Y. Yamada, and Y. Yoshida, J. Polym. Sci., Part A, Polym. Chem., 34, 3531 (1996).

8. T. Iizawa and F. Matsuda, Polym. J., 30, 155 (1998).

9. F. Matsuda, N. Matsuno, and T. Iizawa, Kobunshi Ronbunshu, 55, 439 (1998).

10. (a) R. E. Carter, J. Chem. Phys., 34, 2010 (1961); (b) M. Ishida and C. Y. Wen, AIChE J., 14, 311 (1968).

11. T. Nishikubo and K. Ozaki, Polvm. J., 22, 1043 (1990).

12. a) S. Yagi and T. Kunii, Kogvo Kagaku Zashi, 56, 131 (1953); (b) O. Levenspiel, "Chemical Reaction Engineering," John Wiley \& Sons, Inc., New York, N.Y., 1972, p 372.

13. A. Kameyama, M. Suzuki, K. Ozaki, and T. Nishikubo, Polym. J., 28, 155 (1996). 